\title{
Investment Potential Formation for the Development of Agricultural Enterprises at the Regional Level
}

\author{
Belokopitov A.V.* \\ Smolensk State Agricultural Academy \\ Smolensk, Russia \\ abelokopytov@mail.ru
}

\author{
Matveeva E.E. \\ Smolensk State University \\ Smolensk, Russia \\ matveevaelena2005@yandex.ru
}

\author{
Moskaleva N.V. \\ Smolensk State Agricultural Academy \\ Smolensk, Russia \\ moskalevanata322@rambler.ru
}

\begin{abstract}
The economic reforms in the Russian Federation of the 1990s led to a significant reduction in government intervention in capital market and this primarily affected investment activity of agro-industrial complex. Agricultural sphere of economy was in a critical situation. Due to insufficient attraction of investment, the process of restoration and regulation of agriculture was slowed down, as a result of which the problems regarding long-term economic growth occurred. The significant decline in all agricultural production and the decrease in the competitiveness of national producers in international and national markets indicated the decrease in investment activity of the entire agricultural sector. Obviously, in order to radically change the conditions of agro-industrial organizations, it is necessary to increase the investment component of institutions and, as a result, increase investment flows into the agricultural sector. The growth of investment in agriculture is most often associated with increased competitiveness of agricultural enterprises.
\end{abstract}

Keywords - investment potential, agricultural organizations, agro-industrial complex, investment activity, regional specialization, agro-industrial region, investment activity, agriculture.

\section{INTRODUCTION}

Nowadays, the one of the most important aspects of the economic development of a country is its investment potential. The protection of the economic interests of the state and, accordingly, the increase of the level of investment potential in agricultural sector, ensures balanced investment activity, with the help of which all agricultural investment processes take place.
In the Russian Federation, the term "investment potential" was first introduced into the regulatory documents in 1999 when the Federal Law "On Investment Activities in the Russian Federation, carried out in the form of capital investments" was adopted. The Law provides the following definition: "Investment potential is the availability of opportunities that can be used to achieve specific goals, mainly the capabilities of the invested object, the conditions for long-term investment in a certain asset"[1].

During the characterization of the investment potential of an enterprise, including agricultural sphere, most researchers and economists consider it comprehensively, as an integral mechanism that includes a number of potentials that allow evaluating both its individual and general elements. The main parts of the investment potential ususally include financial, production, labor, land and other potentials [12].

The system for the calculation of the level of investment potential is a complex and sophisticated aspect that requires a lot of attention. Currently, there is no variety of methodological approaches to the assessment of the investment potential of agricultural organizations. However, some scientists identify the most effective methods which allow assessing the investment potential of agriculture in the state or individual regions.

In addition, there is a technique based on cartographic sources, which shows all the specific features of the natural and climatic features of a region. It is made in cartograms and cartographic schemes for convenience. Most often they are used only as an illustrative background for the aforementioned rating techniques. 
Table 1. Approaches to the definition of "investment potential"

\begin{tabular}{|c|l|}
\hline Authors & \multicolumn{1}{c|}{ Definition } \\
\hline Kazakova & $\begin{array}{l}\text { "This is a set of objective indicators, properties, means and capabilities that determine the } \\
\text { potential purchasing power for investments" [2, p.146] } \\
\text { The use of this definition includes all the interests of participants involved in the } \\
\text { investment process }\end{array}$ \\
\hline I.V. Roysman & $\begin{array}{l}\text { "The resource potential of agriculture is a set of objective natural and economic conditions } \\
\text { that influence the course of the reproduction process in agriculture. It is characterized by } \\
\text { the possible volume of agricultural production for a given land quality, provision with } \\
\text { production assets as well as labor force"[6]. }\end{array}$ \\
\hline $\begin{array}{c}\text { S.A. Gorlanov, M.O. } \\
\text { "Rhamshinurov } \\
\text { of productive forces will cause the increase in the value of its individual potential without } \\
\text { changing the size of total production potential if this element is in excess" [3]. }\end{array}$ \\
\hline $\begin{array}{l}\text { D.K. Shevchenko, } \\
\text { V.A. Ashitko }\end{array}$ & $\begin{array}{l}\text { "The totality of organically balanced resources of the production sector within an } \\
\text { enterprise, which determines its ability to produce a certain volume of production" [7]. }\end{array}$ \\
\hline V.G. Gusakov & $\begin{array}{l}\text { "The combination of resources and economic conditions, ensuring the formation of well- } \\
\text { defined capabilities for the production of appropriate quantity and quality of products or } \\
\text { services" [4], [5] }\end{array}$ \\
\hline
\end{tabular}

The problems associated with investments and investment activities are actively studied in economic science. However, this is especially noticeable in the works of foreign classics, who paid due attention to the study of the investment process. This list includes the following authors: J. Keynes, K. Marx, A. Marshall, A. Smith, R. Harrod, J. Hicks, M. Friedman, J. Schumpeter, P. Samuelson and others.

The problems of increasing the investment potential of regional level are studied in the scientific works of Russian scientists and specialists. This list includes the following authors: R.Kh. Adukov, I.V. Volkov, A.G. Granberg, S.Yu. Glazyev, F.V. Ilyin, K.S. Kirova, N.I. Korda, V.K. Krutikov, E.V. Kuzmina, M.D. Mednikova, V.A. Perfilov, I.E. Risin, A.S. Sokolitsyn, G.G. Urbanskaya and others.
These authors consider various aspects of the formation of investment potential in the activities of agricultural regions. However, the issues of the attraction of small and mediumsized agricultural enterprises in investment activities have not been sufficiently studied and require further research.

\section{RESEARCH RESULTS}

In our opinion, in order to develop a region, especially agro-industrial one, it is necessary to focus on objective prerequisites for the formation of investment potential such as the presence and interaction of various elements in the investment process. In addition, the economic development of a region itself is extremely significant.

Figure 1 shows the structure of investment potential of a region.

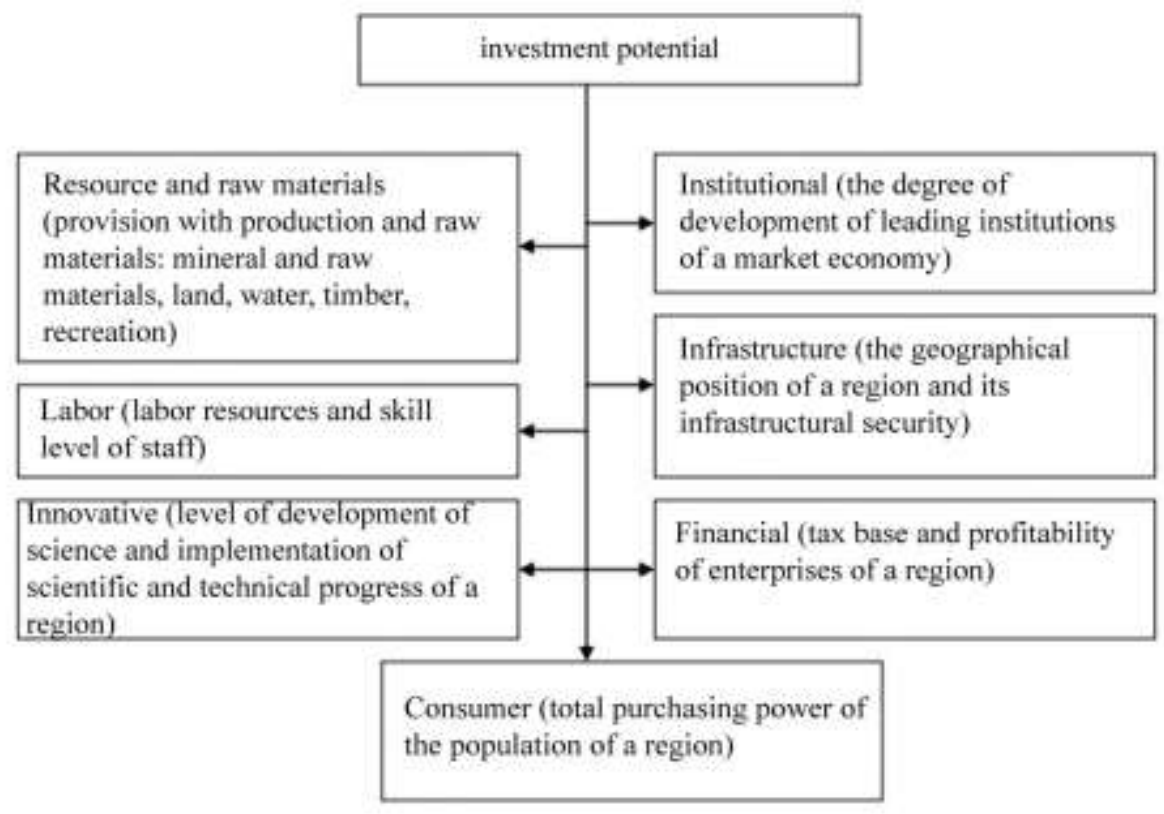

Figure 1. Structure of investment potential of a region 
As a rule, inward investments and capital investments of accumulated character have a constant tendency to decline in the investment potential of a region. In addition, it is necessary to note that Russian investment should be coupled with the regional investment potential, especially if it is an agroindustrial one.

Figure 2 shows the determinants that increase and decrease investment potential and risks in the agricultural region.

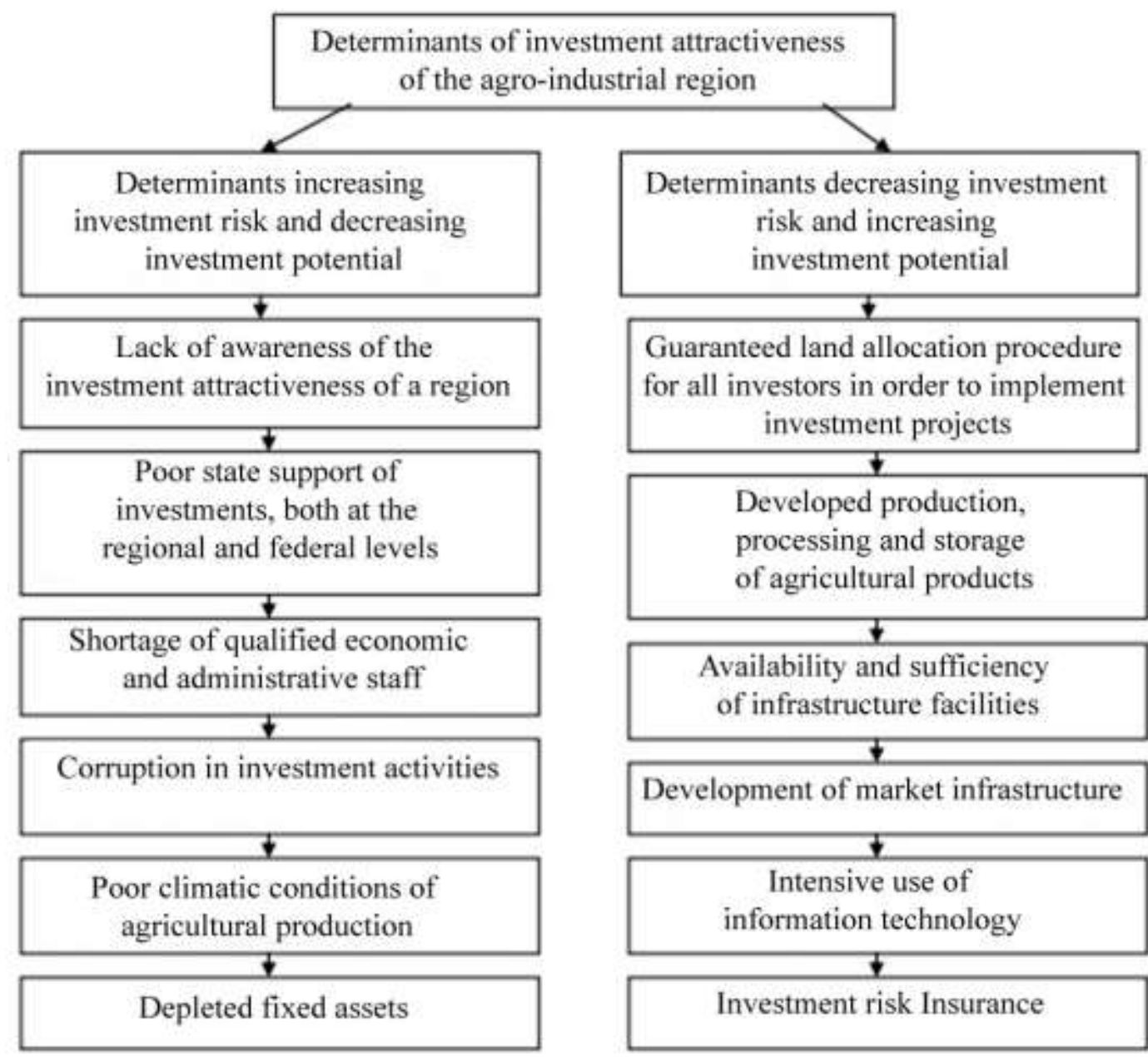

Figure 2. Determinants of negative and positive impact on investment risk and investment potential of the agro-industrial region

As a result, the influence of the majority of diverse factors of investment risk has an ambiguous effect on the formation of investment potential of regions. Moreover, it is difficult to assess both the investment potential of the region and the entire investment activity if it has an agro-industrial orientation.

Smolensk region is in a favorable geographical position in terms of agricultural activities. Due to its location, Smolensk region undoubtedly has great potential in further socioeconomic development and agricultural growth.

By the beginning of 2020, in the Smolensk region there are about 28,000 business entities, about 15,000 medium, small and micro enterprises, as well as about 540 medium and large processing industrial enterprises.

Smolensk region has great investment attractiveness the factors of which are presented in Figure 6. [12]
Today we can say that there is the increase in the material basis of investment potential, which ensures the dynamics of the socio-economic development of agricultural enterprises.

In Table 2, we see that the most investment-attractive sphere of capital investment in the Smolensk region for 2019 is the manufacturing sector of $12,327.4$ million rubles with the increase of $37 \%$ compared to 2018 , as well as a share of $30 \%$ of investments of all economic spheres. The second position is occupied by the sphere of logistic movement and storage with indicators of $11,132.5$ million rubles, which increased by $27 \%$ in the previous similar period with a share of $24 \%$ of all investments in fixed assets. In addition, a significant share is occupied by the forestry, agro-industrial complex and hunting and fishing activities. 


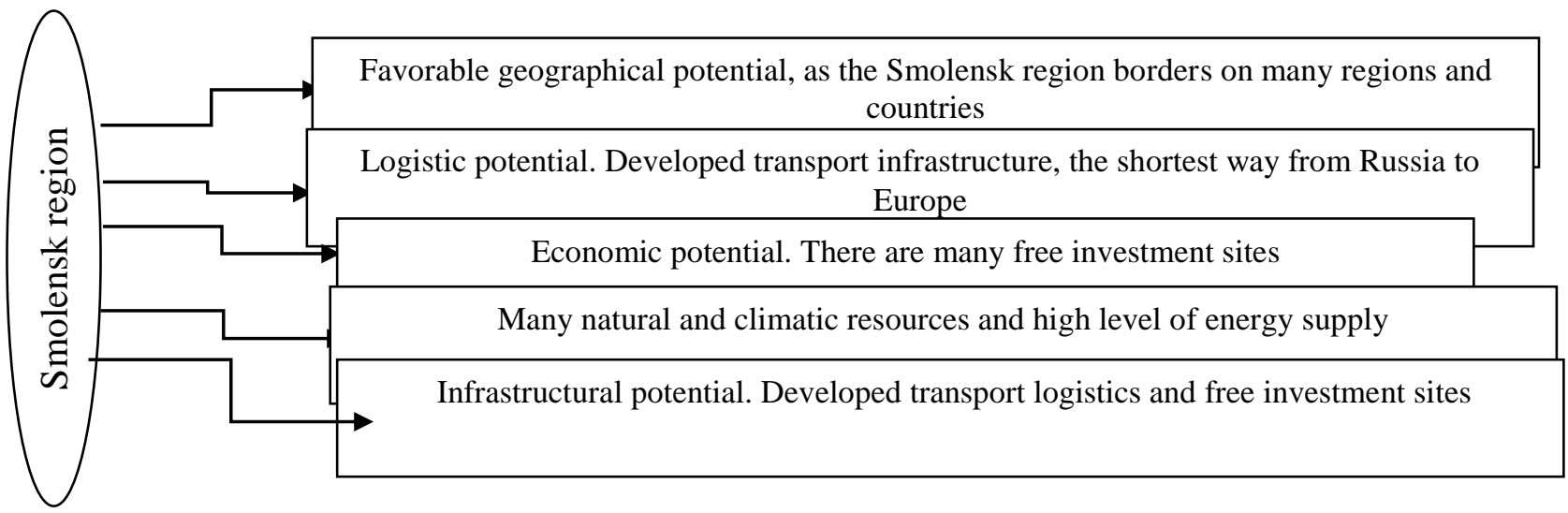

Figure 3. Factors forming investment attractiveness of the Smolensk region

As a result of the development of agricultural sphere, it is necessary to significantly strengthen the material and technical bases of agricultural producers, and it is also necessary to technically re-equip the processing industry enterprises. In order to achieve this goal, significant capital investments and large-scale investments are required, acting as a main condition for the reproduction process [14].

Table 2. Distributions of capital investments in fixed assets by types of economic activity

\begin{tabular}{|c|c|c|c|c|}
\hline \multirow{3}{*}{ Type of economic activity } & \multicolumn{3}{|c|}{2019} & \multirow{3}{*}{$\begin{array}{c}\text { For reference } \\
\text { percentage } \\
\text { comparison } \\
\text { with } 2018 \\
\end{array}$} \\
\hline & \multirow[t]{2}{*}{ Mln. rub. } & \multicolumn{2}{|c|}{ In $\%$} & \\
\hline & & 2018 & Result & \\
\hline Total & 41531,9 & 80,7 & 100 & 100 \\
\hline Agriculture, fishing, hunting and forestry & 2899,0 & 80,1 & 7,0 & 8,4 \\
\hline Mining & 92,7 & 100,6 & 0,2 & 0,2 \\
\hline Manufacturing industry & 12327,4 & 137,5 & 29,7 & 17,6 \\
\hline Air conditioning, electricity, steam and gas & 6751,1 & 42,4 & 16,3 & 31,3 \\
\hline $\begin{array}{l}\text { Water supply and sanitation, waste management, } \\
\text { elimination of environmental pollution }\end{array}$ & 563,9 & 2,1 & 1,4 & 0,5 \\
\hline construction & 826,8 & 2,1 & 2,0 & 0,8 \\
\hline $\begin{array}{l}\text { Wholesale and retail business, repairing motorcycles and } \\
\text { motor vehicles }\end{array}$ & 1118,5 & 81,5 & 2,7 & 2,7 \\
\hline Storage and logistics & 11132,5 & 84,8 & 26,8 & 24,0 \\
\hline Catering and hotel business & 25,1 & 64,5 & 0,1 & 0,1 \\
\hline Information activities in the field of communications & 1314,1 & 89,7 & 3,2 & 2,9 \\
\hline Insurance and financial transactions & 240,2 & 172,0 & 0,6 & 0,3 \\
\hline Real Estate Procedures & 374,8 & 84,9 & 0,9 & 0,9 \\
\hline Scientific and technical activity & 88,0 & 121,1 & 0,2 & 0,1 \\
\hline Administrative activities and related processes & 1014,8 & 5,7 & 2,4 & 0,3 \\
\hline Military Security, State and Social Management & 405,9 & 31,7 & 1,0 & 2,5 \\
\hline Education & 890,9 & 128,3 & 2,1 & 1,4 \\
\hline Social Services and Health & 1078,5 & 38,4 & 2,6 & 5,3 \\
\hline Leisure, sports and culture management & 374,2 & 133,4 & 0,9 & 0,5 \\
\hline Other types of services & 13,4 & 60,0 & 0,0 & 0,1 \\
\hline
\end{tabular}

One of the promising areas of investment is the development of food industry, including meat farming. [9]

In the west of the region in the Gagarinsky district, the company KROL \& Co launched the investment project in 2019. The main focus is on the expansion of production capacities, namely, increase in the rabbit breeding farm in new farm with 15,820 heads of parent livestock and 1,024 heads of progenitor livestock. At the end of the construction of new production facilities and places of keeping animals, the capacity of the enterprise will increase by 2 times. According to the estimates, the amount of investment in this project will exceed 1.1 billion rubles. At the time of 2020, all the initial procedures for the cadastral registration of the land plots planned for development were completed, as well as necessary infrastructure for electricity and gas supply. 
The investors also consider the possibility of increasing processing capacities; the planned completion date of the investment project is 2021. [10]

For the region, this investment project will create the increase of up to 70 skilled jobs, the increase in tax revenues. At the same time, the investment project of Krol \& Co provides tax incentives for property through state support and aims to increase export performance and food production index.

Moreover, the investment project "Krol and Co" has an image advantage for the investment attractiveness of the Smolensk region, as the products are sold under the common regional brand "SMOLPRODUCT", which draws new attention to the region. Moreover, the company collaborates with Russian companies producing baby food, such as Frutoyanya, Babushkino Lukoshko, supplying its products in the form of a rabbit fillet, what attracts new counterparties.

Since 2018, the largest project in the field of dairy farming on the improvement and expansion of the dairy farm from 1,800 to 4,250 in the Safonovsky district has been actively developing by the Golden Niva enterprise.

At present, the number of livestock is 4,500, including 2,365 dairy cows and daily milk production is $70-71$ tons per day. In order to maintain livestock, 7 cowsheds with all necessary equipment were built and fodder base was created. [10]

The company has a complete production cycle from sowing and harvesting feed, to sending milk to the processing. The amount of investments is more than 1.5 billion rubles; new 170 jobs will be created. In order to further increase the dairy livestock, it is planned to reconstruct nearby farm. The financial investments will amount to more than 500 million rubles. In total, it is planned to attract financial inflow of up to 2.2 billion rubles for the entire investment project. It is planned to perform the project until 2021. About 13,000 tons of milk is supplied to the Ehrmann yogurt factories per year, which contribute to the creation of new mutually beneficial economic relations of the region with large Russian companies.

Today, a project is launched to create the Rosa Smolensk Dairy Plant. The project is located on the industrial territory of the former Unimilk Company, which ceased its production in 2014.

The list of products of the plant will stick with standard dairy products. The volume of financial investments in this project is about 230 million rubles. The social benefit will be the creation of 80 new jobs in the regional center.

In March 2020, the Rosa Dairy Plant was opened. The production facilities were completely repaired and the necessary infrastructure for gas, electricity and water supply was installed over the entire period of the investment project.

In March 2019, in the territory of Khislavichisky district, the opening of the high-tech repair and technical base of MIRATORG Company took place for the maintenance, routine and repair work of agricultural machinery and vehicles. The volume of investments amounted to 120 million rubles. As a result, 180 jobs will be created in the region. [10]

In general, in order to increase investment potential of agricultural organizations it is necessary to focus state tools on the modernization of fixed capital used in agriculture. This will allow increasing the competitiveness of the industry and ensuring effective expansion of reproduction [13]. The tools to improve the investment potential of agricultural activities are presented in Figure 4.

The solution of the above-mentioned strategic tasks and the implementation of all tools aimed at the increase of the investment potential of agriculture in the region are possible only if there are prerequisites based on the following principles:

- $\quad$ regional policy focus;

- priority of solving the most acute and urgent economic problems;

- balance of interests of all participants in the investment process (public and private interests);

- simplicity and accessibility of the relationship of participants in the investment process, with the demarcation of responsibility of all parties, the invariability of decisions;

- demand balance of regional administration as a manager of economic activity;

- rational orientation of investment policy in compliance with the adequacy of other areas of expenditure;

- flexibility of the regional investment policy, able to adapt to the changing economic and political situation in accordance with the interests of the subjects of the investment process.

\section{CONCLUSION}

The investment potential of agricultural enterprises in the region is one of the fundamental areas in the process of development and establishment of economic activity. It is necessary to take into account that due to the constant changes in the internal and external factors of the region, the directions and methods of functioning of the investment activity of a region require constant research and modernization if the regional administration is interested in economic and social growth.

The decisions to start or continue investment activity are the most difficult ones. They are based on a multi-criteria and multivariate system of the assessment of a large number of factors and existing trends, which can often even be unrelated [15].

There is no doubt that the competent management of investment potential in all segments of the investment market completely and entirely depends on whether the investment environment in the region improves.

As a result of the development of the investment potential of agricultural enterprises in the region, there is the increase in the interest of agricultural entities in state support, as well as 
the need to streamline policy in order to improve investment relations. It is also possible to increase investment attractiveness by government contracts with future investors, creation of new organizations in the region and buy-out of existing ones, with the possibility of a complete change [16].

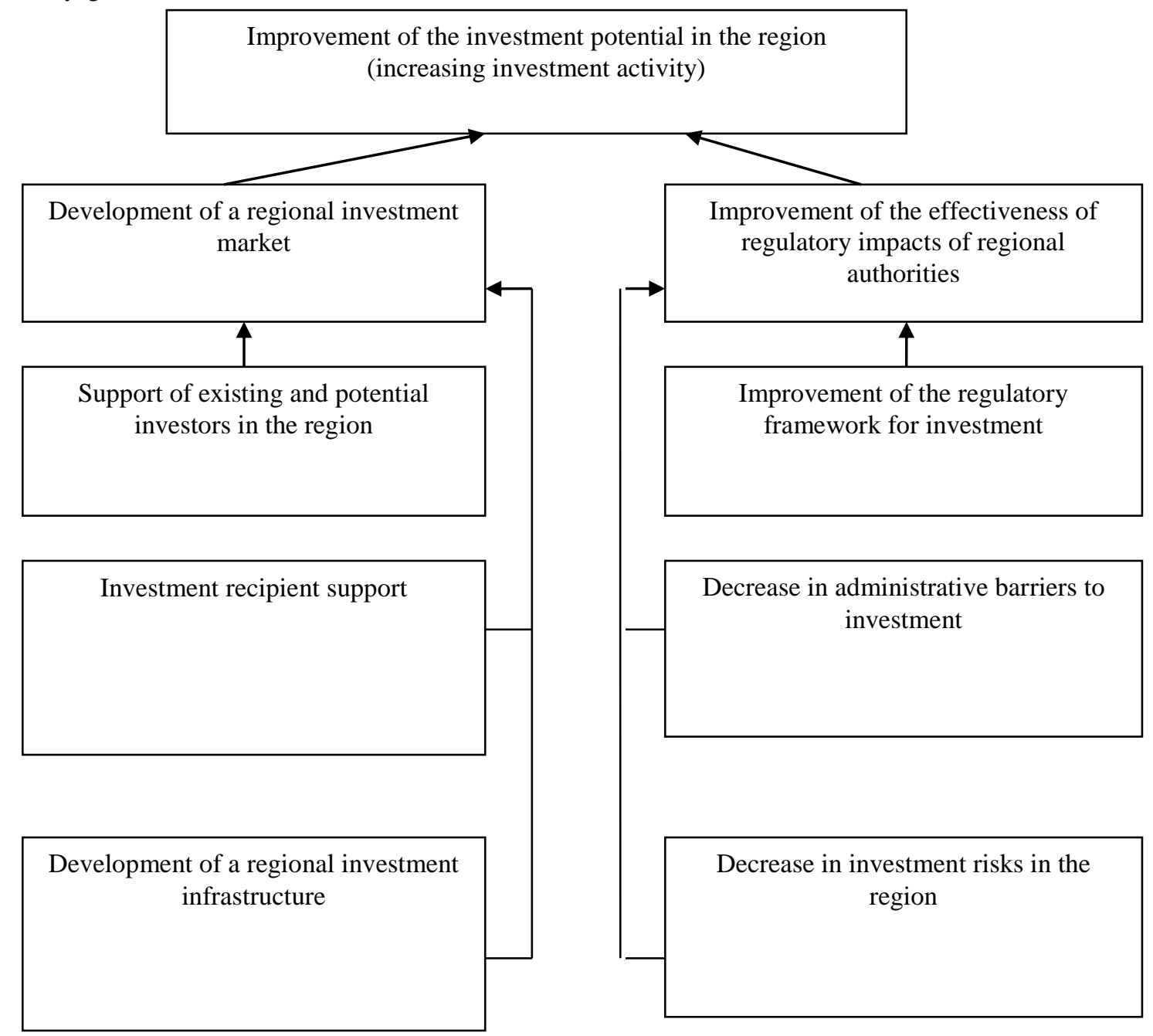

Figure 4. Strategy for the implementation of improvement model of the investment potential of a region in agriculture

\section{References}

[1] Federal Law "On Investment Activities in the Russian Federation in the Form of Capital Investments" dated 02.25.1999 No. 39FZ. Retrieved from: http://www.consultant.ru/document/cons_doc_LAW_22142/

[2] L.S. Valinurova and O.B. Kazakova, 'Investing: theory and practice: a textbook'. Moscow: KNORUS, 2017.

[3] S.A. Gorlanov and M.O. Shamshinurov, "The relationship of the capital cycle and economic growth in agriculture of the region," AIC: Economics and Management. vol. 3, 2012. pp. 86-90.

[4] V.G. Gusakov, Issues of market development of agribusiness: selected works: vol. 2. Minsk: Belaruskaya Navuka, 2012.

[5] V.G. Gusakov, "The main problems of the prospective development of the agro-industrial complex," Veatsyyanalnay academii Nauk Belarusi. Gray agricultural science, vol. 2, 2016. pp. 44-49.

[6] I.I. Roizman, "Modern and perspective typology of the investment climate of the Russian regions," Investments in Russia, vol. 3, 2017. p. 59.
[7] D.K. Shevchenko and V.A. Ashitko "Assessing the flexibility of an enterprise when adapting it to innovative updating," Economics and Entrepreneurship, vol. 3-2(68), 2016, pp. 867-870.

[8] I.G. Ushachev, A.V. Kolesnikov and V.S. Chekalin, "The development of innovation is the most important component of the agrarian policy of Russia," AIC: Economics and Management, vol. 5, 2019, pp. 22-31.

[9] A.G. Ushachev, V.V. Maslova and V.S. Chekalin, "Improving the export potential of the agro-industrial complex on the basis of innovative development," Economics of agricultural and processing enterprises, vol. 10, 2019, pp. 2-5.

[10] The official Investment portal of the Smolensk region. Retrieved from:: https://smolinvest.com/

[11] S.E. Terentyev, O.V. Lazko and A.B. Belokopytov, "Organizational and economic aspects of the implementation of digital technologies in the innovative development of dairy cattle breeding," Proceedings of the 1st international scientific conference: modern management trends and the digital economy: from regional development to global economic growth (MTDE 2019), vol. 81, pp. 46-51, 2019.

[12] S.A. Gorlanov, Z.P. Medelyaeva, V.B. Malitskaya, M.B. Chirkova and E.I. Kostyukova, "Content analysis the term "effectiveness" and the 
concepts of its quantitative characteristics," Indo American Journal of Pharmaceutical Sciences, 2019, vol. 6 (3), pp. 5293-5298.

[13] O.B. Kazakova, I.P. Chernaya, E.P. Makarova and T.E. Kochergina, Policy of the regional support of innovations in developing countries: the search for an institutional model for the russian economy // Ecology, Environment and Conservation. 2016. Vol. 22 (8). pp. AS60-AS63.

[14] V.I. Trukhachev, I.Y. Sklyarov, Y.M. Sklyarova, A.V Volkogonova and V.Z. Mazloev, "Features of investment activity in agriculture in the south of russia and ways of its activation," Montenegrin Journal of Economics, 2018. vol. 14 (1), pp. 171-184.

[15] A.I. Altukhov, A.V. Bogoviz and I.M. Kuznetsov, "Creation of an information system - a necessary condition of rational organization of agricultural production," Advances in Intelligent Systems and Computing, 2019. vol. 726. pp. 800-809.

[16] V.V. Maslova, V.S. Chekalin and M.V Avdeev, "Agricultural development in Russia in conditions of import substitution," Herald of the Russian Academy of Sciences, 2019, vol. 89 (5), pp. 478-485. 